\title{
Subject Superiority Developing Composition Talents Cultivation Mode Based on Comprehensive Safety Discipline
}

\author{
Dan Mei \\ Wuhan University of Science and Technology \\ Hubei Wuhan, China. \\ meidan666@163.com \\ Meng Wen \\ Wuhan University of Science and Technology \\ Hubei Wuhan, China.
}

\author{
Yaoxuan Tao* \\ Wuhan University of Science and Technology \\ Hubei Wuhan, China \\ 1039475911@qq.com \\ Futang Xing \\ Wuhan University of Science and Technology \\ Hubei Wuhan, China
}

\begin{abstract}
The education of the safety engineering is not only the major way to cultivate the professional talents, but also the basis of the safety science development. The paper introduces the development of safety science and engineering in the Chinese colleges. In order to overcome the limitation of the employment of our safety engineering graduated students, depended on the superiority of safety science and engineering in the Wuhan University of Science and Technology, the reform measures are proposed. That is transforming the single professional talents cultivation mode to composite cultivation. They contain that constructing $1+5$ theory teaching system, establishing multi-dimensional the experimental curriculum and platform, and cultivating the innovation ability of students. The object is to cultivate composite talents at the viewpoint of comprehensive safety discipline.
\end{abstract}

Keywords-comprehensive safety discipline; subject construction; composite mode; talents cultivation mode; subject superiority.

\section{THE IMPORTANCE OF CULTIVATING COMPOSITE TALENTS AT THE VIEWPOINT OF COMPREHENSIVE SAFETY DISCIPLINE}

With the progress and development of the economic society, National need for safety engineering professionals is no longer limited to mining, metallurgy and other traditional industries, it has been extended to the petroleum, chemical, machinery, construction, aviation, transportation, information and other fields. In 2014, the revised "safety production law" requirements: "mining, metal smelting, building construction, road transport units and dangerous goods' production, management, storage units, shall set up institutions for the administration of production safety or equipped with full-time personnel for the administration of production safety. Other production and business units who's employees are more than 100 people should be set up institutions for the administration of production safety or equipped with full-time personnel for the administration of production safety; practitioners in less than a hundred people, it should be equipped with full-time or part-time personnel for the administration of production safety. Therefore, the high quality of security professionals in the job market has become a sought after resource.

With the increasing emphasis on the security of the country, it has brought the prosperity of the safety engineering profession, there are 114 colleges and universities who set up safety engineering undergraduate professional, nearly ten thousand graduates each year[1]. How to make our security engineering students to maintain the advantage in the job market in such a large group of graduates? Our school's safety engineering professional employment is narrow, $90 \%$ of the graduates are still concentrated in the construction industry, with the further expansion of the enrollment scale and the limited capacity of the industry, employment pressure will surely appear in the existing training mode. Students with the same background in the same industry development will appear homogeneous competition situation[2]. Therefore, reforming the existing safety engineering personnel training mode and transforming the single type of professional talents to the compound talents so that we can expand the student's employment surface and make the students go to the society successfully, it has the urgent practical significance.

\section{A. Enhance National Security Literacy.}

College students are pillars of the future construction and development of national, at the same time, the university is the best period for students to learn knowledge and skills, It is an important stage of human's personality and psychological quality gradually moving towards maturity, strengthen the safety education for college students will help to enhance the awareness of national security and safety quality and to lay the cornerstone for the construction of safety culture in society. 


\section{B. Strengthen Personal Safety Awareness.}

Safety culture education helps to improve college students' personal safety awareness and prevention awareness, especially in the production process in the industry in future, firmly establish a sense of safety, standardize the behavior of individual security, form the system of safety management and to avoid the occurrence of work, production and life as far as possible.

\section{Meet The Needs of Employment Oriented.}

Constantly adapt to the requirements of the employer to safety production and safety operation. Cultivate high-quality personnel which have a solid professional knowledge, safety consciousness and safety management knowledge, broaden the students' employment ability to achieve schools, enterprises, social win-win situation.

\section{The Main Guiding IdeOlogy of the Construction of COMPOUND TALENTS WITH COMPREHENSIVE SAFETY DISCIPLINE}

Due the various characteristics of safety problem itself, combined with the fact that the distribution of present graduates are the independent choosing profession, two-way choice, and the security professional employers are various, students must have a broad knowledge to get more opportunities and choices and adapt to the needs of the market economy after graduation.

The concept of the comprehensive safety discipline is to make graduates master the general safety science theory and practice method of the various industries and organizations which is suitable for the demand of the wide employment market and to train the general safety management personnel [3]to improve the level of safety and health services in the process of production and business operation of each industry . Therefore, it is the direct embodiment of improving the quality of teaching to exert the advantage of subject and to build a compound talent training system with special characteristics in the concept of comprehensive safety discipline[4].

Our school's safety science and engineering discipline is developed from Mine ventilation and safety professional which was founded in 1987. it changed its name to safety engineering in 1992, it began training safety technology and engineering postgraduates in 1993 and began training doctoral students in the field of metallurgical equipment safety in 2004. Grasped the key timing of national discipline adjustment, it became one of the first units to obtain the national "safety science and Engineering" first level discipline doctoral degree granting rights in 2011. In 2012, the subject was awarded the key subject of Hubei province[5].

Relying on the metallurgical industry background, our safety science and Engineering College doing innovative research with the characteristics of ventilation and dust removal, occupational protection, mine safety, fault diagnosis and control of metallurgical equipment, green manufacturing and safety management, five research directions of industrial dust removal by ventilation and control of occupational hazards, safety technology for metal mines, metallurgy equipment fault diagnosis and risk control, blasting security theory and technology, metallurgy enterprise green manufacturing and production safety management have been formed, which has become China's metallurgical industry's dominant subject.

The main guiding ideology of the study is relying on discipline advantages, based on professional characteristics, breaking the curriculum barriers, building a personnel training system with the comprehensive safety discipline, and strive to cultivate the compound talents of the security industry.

\section{THE INNOVATION PRACTICE OF THE CONSTRUCTION OF COMPOUND PERSONNEL WITH COMPREHENSIVE SAFETY DISCIPLINE TRAINING SYSTEM}

\section{A. Put forward the "1+5" theory teaching system with the concept of comprehensive safety discipline}

Safety engineering professional curriculum system should consist of the following three different levels of knowledge structure:

- Basic knowledge level of mathematics, philosophy, engineering knowledge structure;

- Professional basic knowledge level of system security knowledge structure;

- Professional knowledge level of security technology knowledge structure[6].

Among them, the first level is a compulsory course for the whole school project. The second and third levels constitute the teaching content of safety engineering specialty.

" $1+5$ " teaching system is setting a safe subject foundation in the second level of the curriculum, set up safety system engineering, safety ergonomics and safety principle course; Play the advantages of the school's 5 research directions(Ventilation and dust control, occupational hazard control, metal mine safety technology, metallurgical equipment fault diagnosis, blasting safety theory and technology, enterprise production and operation safety management) in the third level of the curriculum, set up a professional elective course, focus on training compound talents with the knowledge background of comprehensive safety discipline 


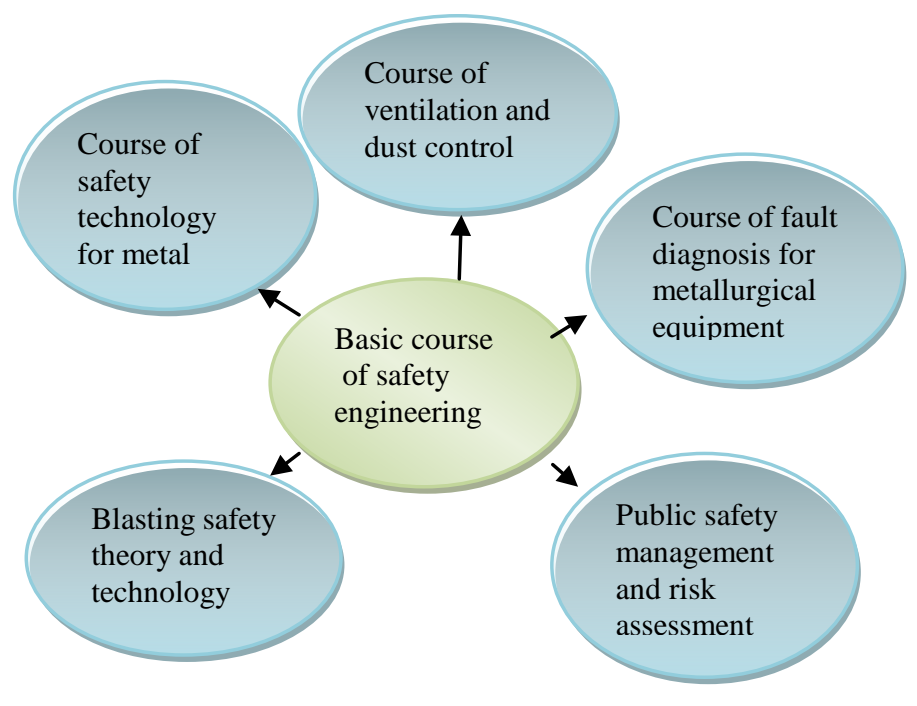

Fig. 1. "1+5" curriculum system

\section{A. Target for Training Compound Talents. Expand the Multi-Dimensional Experimental Space}

Experimental teaching system and experimental teaching platform are unable to adapt to the demand of the development of the discipline since our original safety engineering direction is in the form of second level discipline set in mining engineering discipline, It is necessary to combine the experimental teaching system reform and the experimental platform construction on the basis of the original advantage discipline[7].

To reform and innovation from the experimental teaching mode of exploration[8], experiment teaching supporting system reform and experimental teaching platform construction , Combine the advantages of the subject with the background of mining, metallurgy, blasting and public safety, To expand the students' experimental space by using our iron and steel metallurgy and resources and the Ministry of Education Key Lab , making good use of Hubei Province Key Laboratory of metallurgical equipment, Provincial Department of education and build Key Laboratory of the Ministry and engineering of Ministry of Education Research Center.

\section{B. To Cultivate Innovative Ability As the Guiding Direction, Strengthen Cooperation and Innovation Mechanism}

Colleges and universities have always attached great importance to the cultivation of College Students' innovation ability, and innovation activities are no longer confined to a college or a professional but based on the interdisciplinary advantages of interdisciplinary College under the background of new disciplines[9], The research direction of safety science and engineering disciplines related to multiple colleges include resources, machinery, science and management colleges, the safety engineering is located in the College of resources led, breaking down the barriers, integrating the advantages of resources, leveraging national, provincial College Students' innovative entrepreneurial projects, deepening collaborative innovation mode in order to improve the students' ability of innovation in the subject of interest.

\section{Building a Quality Testing System by Taking the Improvement of Teaching Quality As the Standard.}

The degree of accumulation and job performance of graduates and alumni determined the quality evaluation of university personnel training[10], Whether to cultivate the industry's leading figures and engineering backbone has not only become an important embodiment of the quality of school personnel training, but also an important basis for the survival and development of schools, Based on the above considerations, the quality of personnel training quality monitoring system can be established through the graduation quality research and other measures.

\section{SUMMARY}

Production safety is related to the survival and development of enterprises and related to the safety and health of workers, is highly affected by the state, with the continuous development of economic society, the management system is constantly improving, talents who both understand the technology and the safety management will become the mainstay of all walks of life indispensable, our school give fully play to the advantages of safety science and technology, constructing the " $1+5$ " multidimensional curriculum system and experimental platform, breaking the barriers of departments, expanding students' cooperative innovation mechanism, and cultivating the innovative talents with comprehensive safety discipline. At the same time, we explore the characteristics of the innovative talent training model which can play a role in the field of science and similar colleges and universities.

\section{ACKNOWLEDGEMENT}

This paper is the stage results of Hubei Province Education Department of education teaching and research project "based on the discipline advantage of College Students' safety culture cultivation system research and practice(project number 2015230)" and (project number 2015s017), Wuhan University of science and technology teaching and research project ( project number YJG 201529).

\section{REFERENCES}

[1] Yong Fang Ting, Aihu Cao, Yun Li. Relying on the characteristics of construction industry, optimize the subject construction of(In Chinese) [J]. China Journal of safety science, 2009, 19 (6): 70-76.

[2] LuMeng Li, Qian Liu. American security personnel culture and Its Enlightenment in Auburn University Curriculum Set for 2012 academic annual meeting of the cases / / Proc of both sides of the Taiwan Strait and Hong Kong and Macao area of occupational safety and health conference and China Occupational Safety and Health Association(In Chinese). 2012.

[3] Xiang Wu, WuYi Cheng, Sheng Wang. "On an [J]. universal safety engineering professional training of young teachers" Full(In Chinese), 2014 (8): 66-67. 
[4] Gui Fu, Fu Zhou, Yueping Qin, et al. The safety engineering undergraduate program of "engineering based big security" teaching scheme (In Chinese)[J]. China Safety Science Journal, 2004, 14 (8): 64-67.

[5] Qian Liu, Shuhong Yang, Heyong Yu. Set up in "awarded a doctorate or master's degree in professional directory"The demonstration report of "safety science and Engineering" first class discipline(In Chinese) [J]. Chinese Journal of safety science, 2003,13 (5): 1-4.

[6] Ming Xu, Wuyi Cheng, Yun Luo, et al. Core competitive power of safety science and engineering disciplines compared to(In Chinese)[J]. security,35, 2014 (12): 61-63.

[7] Yongliang Yang, Zenghua Li, Shisong Hou, et al. Exploration and Research on the construction of safety science and engineering experiment teaching platformPractice of(In Chinese) [J]. laboratory science, 2013, 16 (1): 153-155.

[8] Hao Wu, Xiuwen Chi, Xianfeng Chen, et al. Experimental teaching system of safety science excellent engineer(In Chinese) [J].Laboratory research and exploration, 2014, 33 (8): 193-197.

[9] Weizhong Zhang, Zhiwei Huang, Wei Jiang. Study on construction mode of safety engineering specialty in the background of liberal arts(In Chinese) [J]. China Journal of safety science, 2009, 19 (1): 81-85.

[10] Xiaowei Zhai, Jun Deng, highlights the characteristics of the industry in the safety engineering education research (In Chinese)[J].Chinese Journal of safety science, 2008, 18 (1): 90-94. 